Int. J. Electrochem. Sci., 14 (2019) $8532-8543$

\title{
Electrochemically Synthesized Ni@ reduced Graphene Oxide Composite Catalysts for Hydrogen Evolution in Alkaline Media - the Effects of Graphene Oxide Support
}

\author{
Sanjin J. Gutićl ${ }^{\text {, Muharema Šabanović }}{ }^{1}$, Dino Metarapi $^{1}$, Igor A. Pašti ${ }^{2}$, Fehim Korać ${ }^{1}$, \\ Slavko V. Mentus ${ }^{2,3, *}$ \\ ${ }^{1}$ University of Sarajevo, Faculty of Science, Department of Chemistry, Zmaja od Bosne 33-35, 71000 \\ Sarajevo, Bosnia and Herzegovina \\ ${ }^{2}$ University of Belgrade - Faculty of Physical Chemistry, Studentski trg 12-16, 11158 Belgrade, \\ Serbia \\ ${ }^{3}$ Serbian Academy of Sciences and Arts, Knez Mihajlova 35, 11000 Belgrade, Serbia \\ *E-mail: slavko@ffh.bg.ac.rs
}

doi: $10.20964 / 2019.09 .23$

Received: 10 May 2019 / Accepted: 3 July 2019 / Published: 31 July 2019

\begin{abstract}
Graphene-based materials and their role in electrocatalysis related to hydrogen production have been intensively investigated by many authors, often justified through a low price of such materials. In this

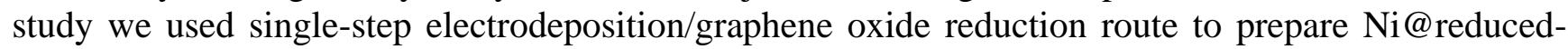
graphene-oxide composites for electrochemical hydrogen evolution reaction (HER). As the precursors for reduced graphene oxide, two different home-made graphene oxides were used. When compared to pure electrodeposited $\mathrm{Ni}$, composite catalysts show improved catalytic activity which depends on $\mathrm{Ni}$ electrodeposition time in a volcano-type fashion. Using electrochemically prepared graphene oxide, HER overvoltage needed to reach $10 \mathrm{~mA} \mathrm{~cm}{ }^{-2}$ was reduced to only $-97 \mathrm{mV}$, showing the improvement by roughly $200 \mathrm{mV}$ when compared to pure electrodeposited $\mathrm{Ni}$. It was concluded that structural disorder and surface oxidation of graphene-based materials are the key properties for reaching high HER activities of such prepared catalysts. Based on this observation, it was discussed whether it is economically justified to use high quality graphene oxide for the preparation of HER catalysts, as the price (production and commercial) of this material can be extremely high, often exceeding the price of platinum.
\end{abstract}

Keywords: reduced graphene oxide; $\mathrm{Ni} / \mathrm{rGO}$ composite; platinum-free electrocatalyst; hydrogen production. 
(C) 2019 The Authors. Published by ESG (www.electrochemsci.org). This article is an open access article distributed under the terms and conditions of the Creative Commons Attribution license (http://creativecommons.org/licenses/by/4.0/). 